OPEN ACCESS

Edited by: Jennifer Rodger, University of Western Australia, Australia

Reviewed by: Adrian Rodriguez-Contreras, City University of New York, USA Manreena Kaur,

Monash University, Australia

*Correspondence:

Paul E. Croarkin

croarkin.paul@mayo.edu

Received: 26 August 2016 Accepted: 17 November 2016

Published: 29 November 2016

Citation:

Lewis CP, Port JD, Frye MA, Vande Voort JL, Ameis SH, Husain MM, Daskalakis ZJ and Croarkin PE (2016) An Exploratory Study of Spectroscopic Glutamatergic Correlates of Cortical Excitability in Depressed Adolescents.

Front. Neural Circuits 10:98. doi: 10.3389/fncir.2016.00098

\section{An Exploratory Study of Spectroscopic Glutamatergic Correlates of Cortical Excitability in Depressed Adolescents}

\author{
Charles P. Lewis ${ }^{1}$, John D. Port ${ }^{1,2}$, Mark A. Frye ${ }^{1}$, Jennifer L. Vande Voort ${ }^{1}$, \\ Stephanie H. Ameis ${ }^{3,4,5}$, Mustafa M. Husain ${ }^{6,7,8}$, Zafiris J. Daskalakis ${ }^{3,4}$ \\ and Paul E. Croarkin ${ }^{1 *}$
}

\begin{abstract}
${ }^{1}$ Mayo Clinic Depression Center, Department of Psychiatry and Psychology, Mayo Clinic, Rochester, MN, USA, ${ }^{2}$ Department of Radiology, Mayo Clinic, Rochester, MN, USA, ${ }^{3}$ Faculty of Medicine, Department of Psychiatry, University of Toronto, Toronto, ON, Canada, ${ }^{4}$ Temerty Centre for Therapeutic Brain Intervention, Campbell Family Mental Health Research Institute, Centre for Addiction and Mental Health, University of Toronto, Toronto, ON, Canada, ${ }^{5}$ The Margaret and Wallace McCain Centre for Child, Youth and Family Mental Health, Campbell Family Mental Health Research Institute, The Centre for Addiction and Mental Health, University of Toronto, Toronto, ON, Canada, ${ }^{6}$ Department of Psychiatry, University of Texas Southwestern Medical Center, Dallas, TX, USA, ${ }^{7}$ Department of Neurology and Neurotherapeutics, University of Texas Southwestern Medical Center, Dallas, TX, USA , ${ }^{8}$ Department of Psychiatry and Behavioral Sciences, Duke University School of Medicine, Durham, NC, USA
\end{abstract}

Introduction: Transcranial magnetic stimulation (TMS) research has suggested dysfunction in cortical glutamatergic systems in adolescent depression, while proton magnetic resonance spectroscopy ( $\left.{ }^{1} \mathrm{H}-\mathrm{MRS}\right)$ studies have demonstrated deficits in concentrations of glutamatergic metabolites in depressed individuals in several cortical regions, including the anterior cingulate cortex (ACC). However, few studies have combined TMS and MRS methods to examine relationships between glutamatergic neurochemistry and excitatory and inhibitory neural functions, and none have utilized TMS-MRS methodology in clinical populations or in youth. This exploratory study aimed to examine relationships between TMS measures of cortical excitability and inhibition and concentrations of glutamatergic metabolites as measured by ${ }^{1} \mathrm{H}-\mathrm{MRS}$ in depressed adolescents.

Methods: Twenty-four adolescents (aged 11-18 years) with depressive symptoms underwent TMS testing, which included measures of the resting motor threshold (RMT), cortical silent period (CSP), short-interval intracortical inhibition (SICl), and intracortical facilitation (ICF). Fourteen participants from the same sample also completed ${ }^{1} \mathrm{H}-\mathrm{MRS}$ in a $3 \mathrm{~T} \mathrm{MRI}$ scanner after TMS testing. Glutamate + glutamine (G|x) concentrations were measured in medial ACC and left primary motor cortex voxels with a TE-optimized PRESS sequence. Metabolite concentrations were corrected for cerebrospinal fluid (CSF) after tissue segmentation. Pearson product-moment and Spearman rank-order correlations were calculated to assess relationships between TMS measures and [GIX].

Results: In the left primary motor cortex voxel, [Glx] had a significant positive correlation with the RMT. In the medial ACC voxel, [GIX] had significant positive correlations with ICF at the 10-ms and 20-ms interstimulus intervals (ISIs). 
Conclusion: These preliminary data implicate glutamate in cortical excitatory processes measured by TMS. Limitations included small sample size, lack of healthy control comparators, possible age- and sex-related effects, and observational nature of the study. Further research aimed at examining the relationship between glutamatergic metabolite concentrations measured through MRS and the excitatory and inhibitory physiology measured through TMS is warranted. Combined TMS-MRS methods show promise for future investigations of the pathophysiology of depression in adults as well as in children and adolescents.

Keywords: transcranial magnetic stimulation, proton magnetic resonance spectroscopy, depression, child and adolescent, cortical excitability, glutamate

\section{INTRODUCTION}

Depression is common in youth, affecting $5.7 \%$ of US adolescents aged 12-17 (Pratt and Brody, 2014). However, the neurobiological mechanisms of depression in this age group remain inadequately understood and may differ from those in adults, as numerous systems with putative roles in the pathophysiology of depression undergo significant developmental changes (Zalsman et al., 2006). Several converging lines of neurophysiological and neurochemical evidence point to glutamate and $\gamma$-aminobutyric acid (GABA), respectively the mammalian brain's predominant excitatory and inhibitory neurotransmitters, as central to the etiology of depression (Krystal et al., 2002; Sanacora and Saricicek, 2007; Levinson et al., 2010; Croarkin et al., 2011). Transcranial magnetic stimulation (TMS) involves the induction of electric current in the cerebral cortex by a focused magnetic field, which permits noninvasive, in vivo investigation of excitatory and inhibitory neural circuits mediated by glutamate and GABA. Studies utilizing pharmacologic agents with known effects at specific neurotransmitter receptors have helped to elucidate the mechanisms of various single- and paired-pulse TMS paradigms (Ziemann et al., 1996a, 2015; Siebner et al., 1998; Werhahn et al., 1999). These include measures of cortical excitability, such as the resting motor threshold (RMT) and intracortical facilitation (ICF), as well as indices of cortical inhibitory processes, such as the cortical silent period (CSP), short-interval intracortical inhibition (SICI), and long-interval intracortical inhibition (LICI; Hanajima and Ugawa, 2008; Sandbrink, 2008; Wolters et al., 2008; Ziemann et al., 2015). TMS has been utilized to investigate disturbances in excitatory and inhibitory systems in a range of psychopathology in adults, including depression (Steele et al., 2000; Bajbouj et al., 2006; Lefaucheur et al., 2008; Levinson et al., 2010). A meta-analysis of adult studies found reductions in CSP duration and reduced SICI in adults with major depressive disorder (MDD) compared to healthy controls, although no consistent differences in RMT or ICF (Radhu et al., 2013). Few studies have examined TMS measures of cortical inhibition and facilitation in children and adolescents with depression. However, our group previously found increased ICF, but no differences in inhibitory measures, in children and adolescents with MDD compared to healthy controls (Croarkin et al., 2013). In a post hoc analysis of the same sample, measures of depression severity showed significant correlations with CSP duration as well as ICF (Lewis et al., 2016). These preliminary findings suggest that children and adolescents with depression may have distinct excitatory and inhibitory cortical physiology compared to depressed adults.

Proton magnetic resonance spectroscopy $\left({ }^{1} \mathrm{H}\right.$-MRS) is a magnetic resonance imaging (MRI) modality that allows quantification of various compounds in live tissue, including brain (Figure 1). Glutamate (Glu) and its related metabolite glutamine (Gln) have overlapping peaks in the ${ }^{1} \mathrm{H}-\mathrm{MR}$ spectrum. Consequently, the sum of their MR signals (Glx), which also incorporates minor signal contributions from GABA and glutathione, is often reported (Maddock and Buonocore, 2012). Multiple prior studies examined ${ }^{1} \mathrm{H}-\mathrm{MRS}$ measures of excitatory and inhibitory neurochemistry in adults with mood disorders (Yildiz-Yesiloglu and Ankerst, 2006; Yüksel and Öngür, 2010). In adult studies, patients with MDD had reductions in glutamatergic metabolites (Glx, Glu, or both) compared to healthy controls in the anterior cingulate cortex (ACC; Auer et al., 2000; Pfleiderer et al., 2003; Hasler et al., 2007; Horn et al., 2010; Merkl et al., 2011; Portella et al., 2011), other prefrontal cortical regions (Michael et al., 2003a; Hasler et al., 2007) and anterior temporal structures (Michael et al., 2003b; Block et al., 2009). Conversely, in one study glutamate levels were elevated in the occipital cortex of depressed adults (Sanacora et al., 2004). Additionally, cortical decrements in ${ }^{1} \mathrm{H}$-MRS-measured glutamatergic metabolites have been shown to normalize with remission (Hasler et al., 2005; Taylor et al., 2009) and with response to treatment (Michael et al., 2003a,b; Pfleiderer et al., 2003). Several ${ }^{1} \mathrm{H}$-MRS studies have investigated glutamatergic abnormalities in depressed, medication-naïve children and adolescents (Kondo et al., 2011), finding decreases in concentrations of Glx (Mirza et al., 2004; Rosenberg et al., 2004) and Glu (Rosenberg et al., 2005) in the ACC, but no decreases glutamatergic metabolites in the occipital cortex (Mirza et al., 2004; Rosenberg et al., 2005), when compared to healthy control youth. In summary, ${ }^{1} \mathrm{H}$-MRS studies to date have yielded substantial evidence of glutamatergic disturbances in adults with unipolar depression, particularly in the ACC, while several adolescent studies have indicated a similar pattern of altered glutamatergic neurochemistry in depression. 


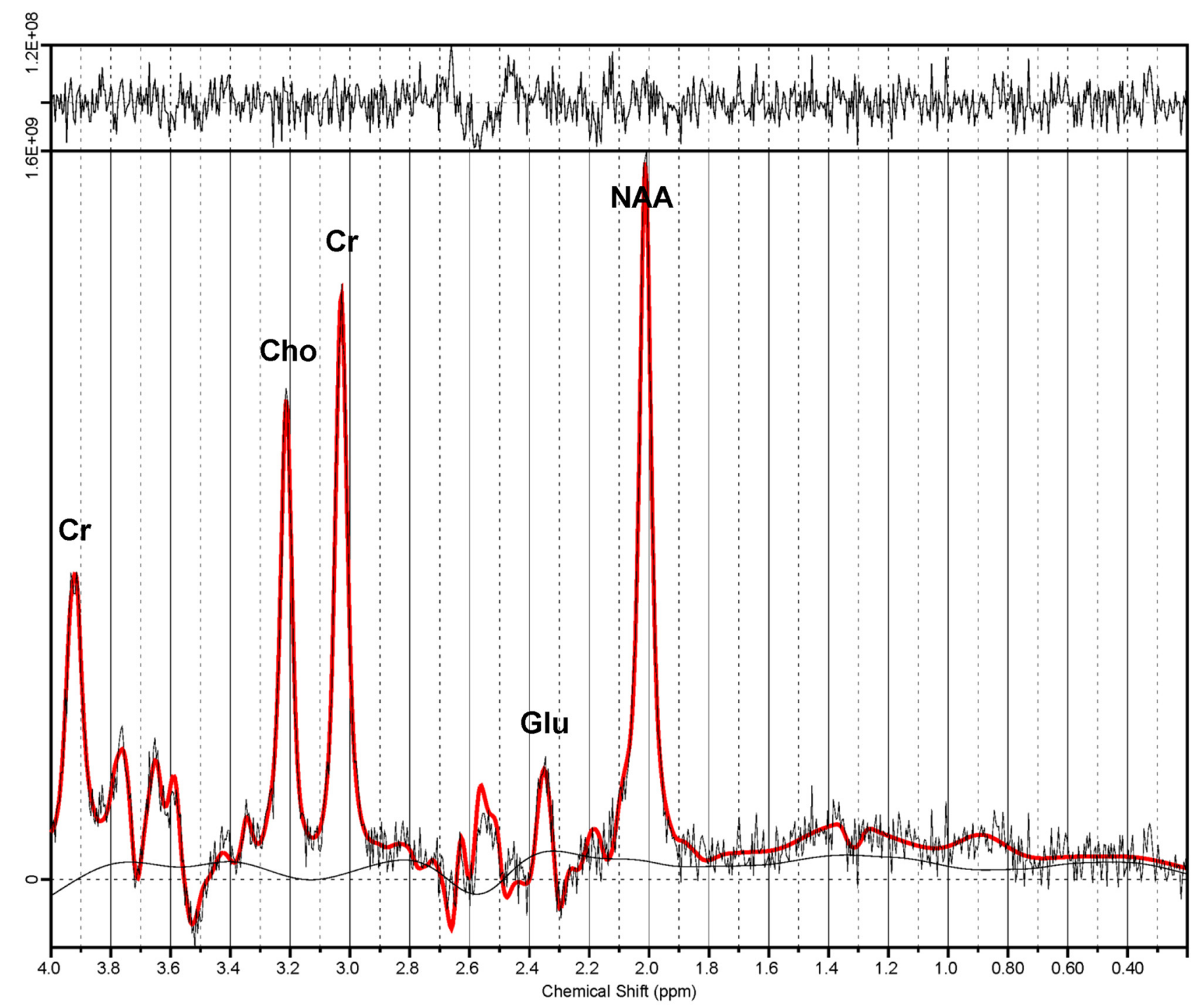

FIGURE 1 | Proton magnetic resonance spectrum from the anterior cingulate cortex (ACC). Spectroscopic data were acquired via a TE-optimized PRESS sequence (TE $80 \mathrm{~ms}$ ) at 3 T. Quantitative analysis was performed by LCModel (Provencher, 1993). Note the dominant glutamate (Glu) peak at 2.34 ppm. Also shown are signal peaks of choline (Cho), creatine $(\mathrm{Cr})$ and $n$-acetylaspartate (NAA).

The use of neurophysiologic TMS paradigms in conjunction with MRS permits the assessment of relationships between cortical circuitry functioning and brain neurochemistry (Bestmann and Feredoes, 2013). However, to date this promising approach has seldom been utilized. Two previous studies have examined relationships between TMS measures of cortical excitability and inhibition and ${ }^{1} \mathrm{H}$-MRS-measured glutamate in healthy adults. Stagg et al. (2011) found that the slope of the motor evoked potential (MEP) input-output (I-O) curve, a TMS measure of excitability, correlated strongly with ${ }^{1} \mathrm{H}$-MRS-measured [Glu] and [GABA] in the corresponding primary motor cortex. By contrast, Tremblay et al. (2013) found a positive correlation between motor cortex [Glx] and CSP duration (which persisted when controlling for GABA concentration), but the authors found no correlation between ${ }^{1} \mathrm{H}$-MRS-measured [GABA] and CSP, SICI, or LICI. Few studies have utilized combined TMS-MRS methods in psychiatric populations, and those that have done so typically examined treatment-induced changes in excitatory and inhibitory neurochemistry following repetitive transcranial magnetic stimulation (rTMS) for depression (Croarkin et al., 2016; Dubin et al., 2016). To our knowledge, no prior studies, either adult or pediatric, have examined the associations between TMS measures of excitatory and inhibitory neurophysiology and MRS-measured glutamatergic neurochemistry in depressed individuals. The current exploratory study aimed to investigate relationships between concentrations of ${ }^{1} \mathrm{H}$-MRS-measured glutamatergic metabolites (Glx) and TMS measures of cortical excitability (RMT, ICF) and inhibition (CSP, SICI) in a sample of depressed 
adolescents. For ${ }^{1} \mathrm{H}$-MRS, a left primary motor cortical voxel directly under the location of the TMS coil was selected to examine glutamatergic metabolites in the stimulated region of cortex. Another voxel was selected in the ACC, a structure that has complex roles in the pathophysiology of mood disorders, is often reliably studied with ${ }^{1} \mathrm{H}-\mathrm{MRS}$, and has numerous motor projections (Devinsky et al., 1995; Paus, 2001). We anticipated that TMS measures of glutamatemediated excitability (particularly ICF) would correlate directly with ${ }^{1} \mathrm{H}$-MRS-measured [Glx] in both the ACC and motor cortex.

\section{MATERIALS AND METHODS}

\section{Study Design and Overview}

This was a cross-sectional study of depressed, treatmentseeking adolescents. All participants underwent diagnostic and clinical assessments and TMS neurophysiology measures. A subset of eligible participants underwent MRI/MRS. The TMS measures were obtained during a single session, and MRI/MRS was subsequently performed on the same day. No treatment was provided as part of the study protocol, but following completion, participants were referred for additional care if clinically appropriate. Prior to enrollment, the study protocol and all procedures were approved by the Mayo Clinic institutional review board. Participants under the age of 18 years granted written assent, and parents or legal guardians gave written informed consent. Participants who were 18 years of age provided written consent.

\section{Participants}

The sample was comprised of 24 participants, aged 11-18 years, with clinically significant depressive symptoms. All participants were right-handed as determined by the Edinburgh Inventory (Oldfield, 1971). Additionally, all participants were fluent in the English language, and at least one parent or guardian also was fluent in English. Exclusion criteria included a primary psychiatric diagnosis other than a depressive disorder; history of unprovoked seizures, febrile seizures, seizure disorder or family history of epilepsy; significant positives on the TMS Adult Safety Screen (Keel et al., 2001); implanted metal in the head or other contraindications to MRI/MRS (of note, adolescents were eligible for participation in the study if they had metallic orthodontic hardware, although they were excluded from the MRI/MRS portion of the protocol); prior brain surgery or risk for increased intracranial pressure; pregnancy or suspected pregnancy; or other unstable medical conditions. Additionally, participants at risk of imminent self-harm or suicide as determined by a study psychiatrist (CPL, JLVV, PEC) were not eligible for participation.

\section{Depression Severity Measures}

Participants' depressive symptoms were assessed with two instruments. The Children's Depression Rating Scale-Revised (CDRS-R; Poznanski et al., 1984) is a 17-item, clinician-rated scale that incorporates both parent- and adolescent-reported data into composite scores for specific depressive symptoms. The CDRS-R clinician total score is reported. The Quick Inventory of Depressive Symptomatology-Adolescent (17 Item)-SelfReport (QIDS- $\mathrm{A}_{17}-\mathrm{SR}$ ) is a self-report version of the clinicianrated QIDS- $A_{17}-\mathrm{C}$ (Bernstein et al., 2010), a 17-item assessment of depressive symptoms. The QIDS- $\mathrm{A}_{17}-\mathrm{SR}$ total score is reported.

\section{TMS Procedures and Measures}

All participants underwent TMS to assess cortical inhibition and excitability. Single- and paired-pulse stimulation paradigms were applied to the left primary motor cortex, and measures were obtained via surface electromyography (EMG) of the contralateral (right) abductor pollicis brevis (APB) muscle during TMS stimulation. Participants and research personnel wore earplugs throughout the procedure.

Two Magstim 200 stimulators with a BiStim module (Magstim Co. Ltd., Whitland, Wales, UK) and a figure-ofeight electromagnetic coil $(70 \mathrm{~mm}$ diameter for each coil loop) were used. The coil was positioned tangentially on the surface of the scalp, superficial to the left primary motor cortex. In order to locate the optimal coil position, the position was adjusted in $1-\mathrm{cm}$ increments while stimulating with single magnetic pulses and observing for the maximal contraction of the contralateral APB while the muscle was at rest. After determining the optimal position of the coil for APB stimulation, pulse intensity was increased gradually until the MEP on EMG reached at least 50 microvolts in 5 of 10 trials (Figure 2A); the intensity at which this occurred was defined as the RMT (Rossini et al., 2015). After establishing the RMT, other single- and paired-pulse measures were acquired.

Paired-pulse measures involved the application of two paired magnetic pulses in rapid succession to the left primary motor cortex, again while the APB was at rest. For both SICI and ICF paradigms, a subthreshold conditioning stimulus $(80 \%$ of RMT) was followed by a suprathreshold test stimulus (calibrated to result in an MEP with a peak-to-peak amplitude of $1 \mathrm{mV}$ on EMG). The interstimulus intervals (ISIs) between conditioning and test stimuli were $2 \mathrm{~ms}$ and $4 \mathrm{~ms}$ for the SICI paradigm (Figure 2B) and were $10 \mathrm{~ms}, 15 \mathrm{~ms}$, and $20 \mathrm{~ms}$ for the ICF paradigm (Figure 2C). For both SICI and ICF, the amplitude of the conditioned MEP occurring after the test stimulus is expressed as a ratio to the mean unconditioned MEP amplitude. Paired-pulse measures were obtained in a randomized and counterbalanced fashion, with a total of twelve trials at each ISI. MEP amplitude ratios were averaged for each ISI.

To measure the CSP duration, participants maintained tonic, voluntary contraction of the right APB (at 20\% of maximum contraction strength, measured by hand-held dynamometer), during which single magnetic pulses at $140 \%$ of the RMT were applied to the left primary motor cortex. The CSP was recorded via EMG of the right $\mathrm{APB}$ following each pulse (Figure 3). CSP duration was averaged over the 10 trials performed. 


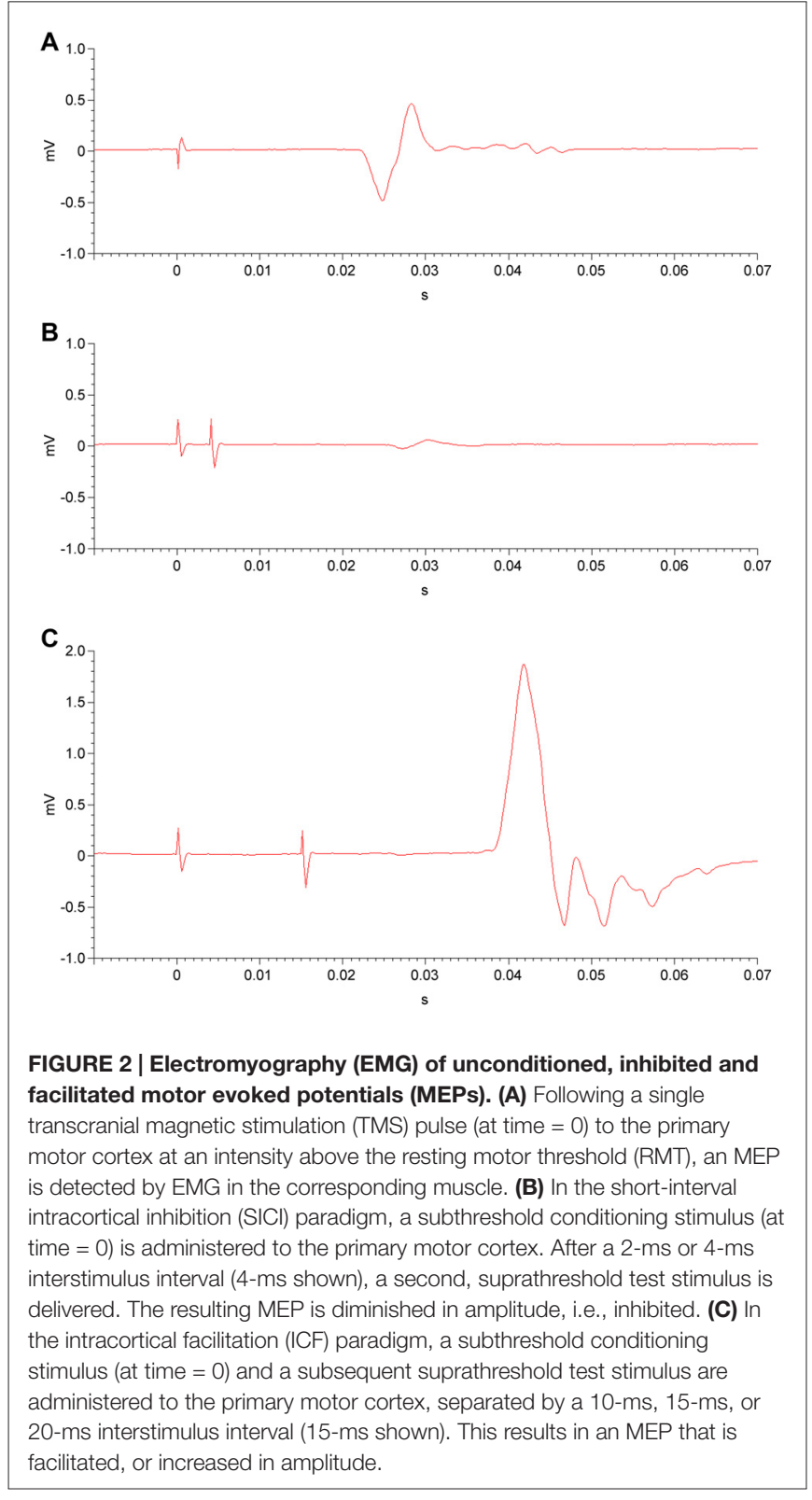

At the conclusion of the TMS session, the position of the center of the TMS coil was marked with a vitamin E capsule, affixed to the scalp with adhesive, as a point of reference for the primary motor cortex during the ${ }^{1} \mathrm{H}-\mathrm{MRS}$ scan.

\section{TMS Measures of Cortical Inhibition}

Two TMS measures that index GABAergic cortical inhibition were obtained. SICI is induced by paired TMS pulses: an initial, subthreshold conditioning stimulus followed 1-5 ms later by a suprathreshold test stimulus, with a resultant MEP that is diminished in amplitude compared to an unconditioned MEP (Kujirai et al., 1993; Ziemann et al., 1996b; Fisher et al., 2002; Ilić et al., 2002). Prior research has implicated intracortical GABAergic inhibitory circuits in

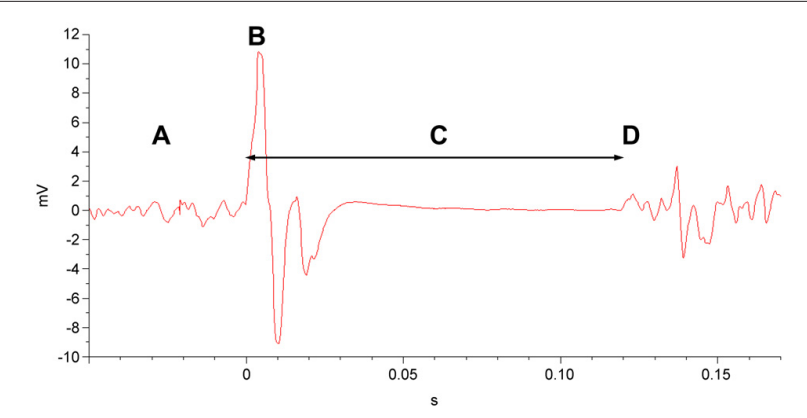

FIGURE 3 | EMG of the cortical silent period (CSP). In a muscle exhibiting tonic motor activity (A), a single TMS pulse at $140 \%$ of the RMT (B) is delivered to the corresponding area of the primary motor cortex. This is followed by the CSP (C), a quiescent interval that ends with resumption of motor activity (D).

the origins of SICI (Di Lazzaro et al., 1998; Hanajima et al., 1998, 2003). Previous TMS-pharmacologic studies have indicated that SICI results from $\mathrm{GABA}_{\mathrm{A}}$ receptor-mediated neurotransmission in the motor cortex (Di Lazzaro et al., 2000, 2005; Ilić et al., 2002; Ziemann, 2004; Hanajima and Ugawa, 2008; Ziemann et al., 2015), specifically those $\mathrm{GABA}_{\mathrm{A}}$ receptors containing $\alpha 2$ or $\alpha 3$ subunits (Di Lazzaro et al., 2007).

The CSP is an interval following a single suprathreshold TMS pulse during which the EMG is quiescent, indicating an interruption in voluntary motor activity (Day et al., 1989a,b; Cantello et al., 1992). The CSP can persist as long as $300 \mathrm{~ms}$, and while spinal inhibitory neurons are thought to contribute to the first $50-75 \mathrm{~ms}$, the latter portion of the CSP is posited to be produced by inhibition of motor cortical origin (Day et al., 1989b; Fuhr et al., 1991; Wolters et al., 2008; Ziemann et al., 2015). Studies involving pharmacologic agents with known effects on GABA receptors have implicated activation of both $\mathrm{GABA}_{\mathrm{A}}$ and $\mathrm{GABA}_{\mathrm{B}}$ receptors in the production of the CSP (Werhahn et al., 1999; Ziemann et al., 2015).

\section{TMS Measures of Cortical Excitability}

By convention, the motor threshold is defined as the lowest magnetic stimulus intensity at which an MEP is reliably produced on EMG in the target muscle (Rossini et al., 2015). The motor threshold is considered to represent excitability of cortico-cortical neurons and their synapses onto corticospinal neurons (Ziemann et al., 2015). The RMT is believed to index glutamatergic synaptic activity more specifically than the active motor threshold (AMT), which may depend to a greater extent on corticospinal and spinal axonal excitability (Paulus et al., 2008). Di Lazzaro et al. (2003) demonstrated that the $N$-methyl-D-aspartate (NMDA) glutamatergic antagonist ketamine causes dose-dependent reductions in the RMT, possibly through enhancement of non-NMDA, $\alpha$-amino3-hydroxy-5-methyl-4-isoxazolepropionic acid (AMPA) receptor-mediated fast glutamatergic neurotransmission (Paulus et al., 2008; Ziemann et al., 2015). However, other 
NMDA antagonists such as memantine (Schwenkreis et al., 1999) and dextromethorphan (Ziemann et al., 1998) have not demonstrated effects on the RMT. The receptor-nonspecific antiglutamatergic medication riluzole has been shown to increase RMT over time (Schwenkreis et al., 2000). As such, RMT is thought to depend largely on a combination of both NDMA receptor and AMPA receptor-mediated neurotransmission.

Like SICI, ICF involves pairing a subthreshold conditioning stimulus with a suprathreshold test stimulus, albeit with a slightly longer ISI of 7-20 ms. However, pairing TMS pulses in this longer ISI range leads to MEPs that are increased in amplitude (i.e., facilitated) compared to unconditioned MEPs (Kujirai et al., 1993; Ziemann et al., 1996b, 2015; Di Lazzaro et al., 2006; Hanajima and Ugawa, 2008). It has been proposed that ICF originates in the motor cortex as opposed to spinal neurons, and it is hypothesized to be caused by a population of cortical interneurons distinct from those responsible for SICI (Ziemann et al., 1996b; Hanajima et al., 1998), although its mechanisms may be more complex than those of SICI (Di Lazzaro et al., 2006). TMS-pharmacological research has shown the ICF effect to vary with agents that act at $\mathrm{GABA}_{\mathrm{A}}$ receptors (Ziemann et al., 1996a) as well as with medications acting on NMDA receptors (Liepert et al., 1997; Ziemann et al., 1998; Schwenkreis et al., 1999) and by other glutamatergic mechanisms (Schwenkreis et al., 2000). Although ICF is a complex phenomenon in which several neurotransmitters are involved, it has been proposed as an index of cortical excitability mediated predominantly by glutamatergic neurotransmission (Hanajima and Ugawa, 2008; Ziemann et al., 2015).

\section{MRS Procedures and Measures}

\section{MRI and ${ }^{1} \mathrm{H}-\mathrm{MRS}$ Acquisition}

Participants underwent structural MRI and TE-optimized proton MRS using a method similar to that published previously (Croarkin et al., 2016). Briefly, scans were obtained using a General Electric $3 \mathrm{~T}$ Discovery MRI scanner (GE Medical Systems, Inc., Waukesha, WI, USA) equipped with an 8-channel head coil. Volumetric data for the cerebrospinal fluid (CSF) correction were acquired using a FAST 3D SPGR sequence (sagittal acquisition, $\mathrm{TR}=7.4 \mathrm{~ms}, \mathrm{TE}=3.0 \mathrm{~ms}$, flip angle $=8^{\circ}$, voxel $1.02 \mathrm{~mm}^{3} \times 1.02 \mathrm{~mm}^{3} \times 1.2 \mathrm{~mm}^{3}$ ). Structural MRI scans were reviewed by a neuroradiologist (JDP) for incidental findings.

A systematic approach to voxel positioning was followed for all participants (Figure 4). During the TMS procedure, a vitamin $\mathrm{E}$ capsule was affixed to the scalp overlying the left APB point. For the left primary motor cortex voxel, a set of axial oblique localizer slices were placed parallel to the scalp/calvarium centered on the vitamin $\mathrm{E}$ capsule. An $8 \mathrm{~cm}^{3}$ voxel $(2 \mathrm{~cm} \times 2 \mathrm{~cm} \times 2 \mathrm{~cm})$ was placed on one of the oblique localizer slices such that: (1) the voxel was centered on the vitamin E capsule; and (2) the voxel was positioned as superficially as possible on the left precentral gyrus such that the outer margin of the voxel did not enter the calvarium. This region encompassed the hand knob of the precentral gyrus (Brodmann area 4) that was presumably interrogated with TMS. The ACC voxel was positioned as previously described (Croarkin et al., 2016), encompassing the pregenual ACC of both hemispheres (Brodmann areas 24a, $24 \mathrm{~b}$ and 32). A TE-optimized PRESS sequence (PROBE-P, $\mathrm{TR}=2000 \mathrm{~ms}, \mathrm{TE}=80 \mathrm{~ms}, 128$ acquisitions, $5000 \mathrm{~Hz}$ bandwidth, 2048 points) was used to obtain spectroscopic data for both voxel locations.

\section{Reconstruction and Quantification of Spectra}

After acquisition, the spectroscopic imaging data were transferred to a UNIX workstation running SAGE-IDL (GE Medical Systems, Inc., Waukesha, WI, USA). Visual verification of data integrity was performed, with scans demonstrating significant artifact being excluded from analysis. Quantitative analysis of metabolites was performed with LCModel software (Provencher, 1993), with the basis set provided by the vendor. A CramérRao lower bound of 20 (for measurement of error) was used, and data with bounds higher than 20 were excluded (Kreis, 2016).

\section{Tissue Segmentation and CSF Correction}

Anatomical image data was segmented into gray matter (GM), white matter (WM), and CSF as previously described (Port et al., 2008; Croarkin et al., 2016). Briefly, voxel locations were superimposed upon the segmented anatomical data, and the fractions of GM, WM, and CSF were summed for each imaging pixel in the spectroscopy voxel. The fraction of $\mathrm{CSF}\left(\mathrm{F}_{\mathrm{CSF}}\right)$ in each spectroscopy voxel was computed and used to correct metabolite concentrations:

$$
[\mathrm{M}]_{\text {Corrected }}=[\mathrm{M}]_{\text {Measured }} \times\left(\frac{1}{1-\mathrm{F}_{\mathrm{CSF}}}\right)
$$

CSF-corrected metabolite concentrations are reported in "institutional units." All statistical analyses were performed with CSF-corrected concentrations of metabolites. ${ }^{1} \mathrm{H}$-MRS spectra yielded CSF-corrected concentrations of the following metabolites in the ACC and left motor cortex voxels: creatine $(\mathrm{Cr})$, choline (Cho), $n$-acetylaspartate (NAA), glutamate (Glu), and glutamate + glutamine (Glx).

\section{Statistical Analysis}

To assess relationships between TMS measures and glutamatergic metabolite concentrations, correlation coefficients were calculated for each TMS measure and [Glx] in each voxel, with an $\alpha$ level of 0.05 (two-tailed) for significance. Distributions of TMS measures of cortical excitability and inhibition and ${ }^{1} \mathrm{H}$-MRS-measured Glx concentrations in each voxel were assessed for normality using the Shapiro-Wilk test. [Glx] in both voxels and all TMS neurophysiologic measures demonstrated normal distributions by the Shapiro-Wilk test, with the exception of the MEP amplitudes in the 2-ms SICI paradigm ( $W=0.8507, p=0.0227)$ and the 20 -ms ICF paradigm ( $W=0.7281, p=0.0007)$. However, visual inspection of 

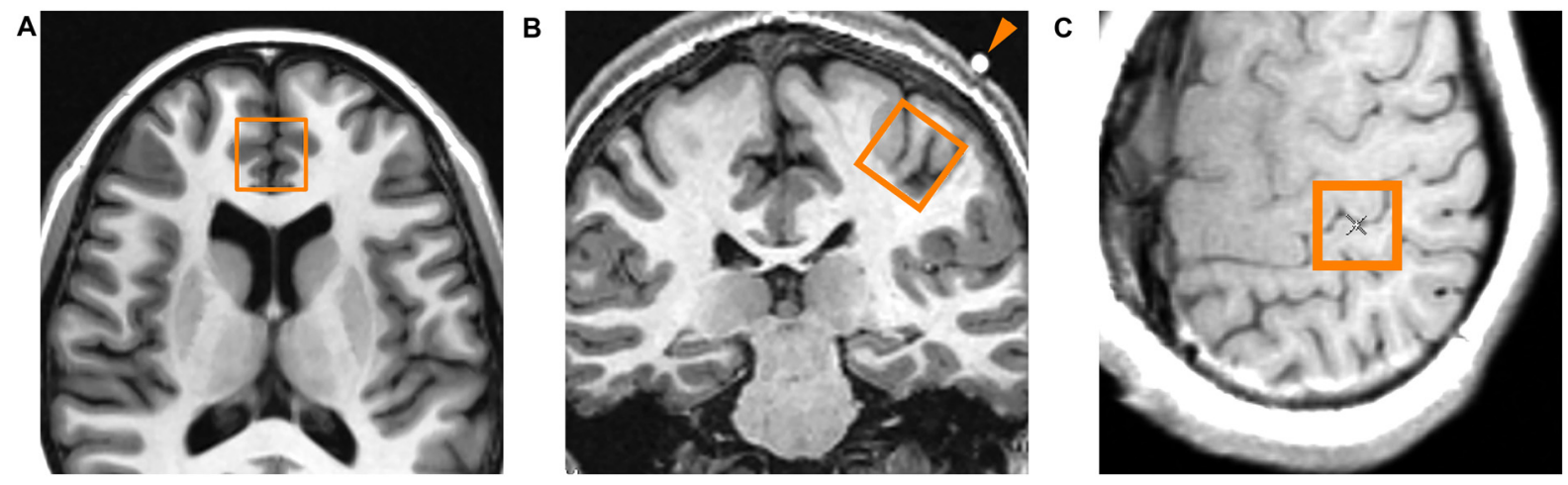

FIGURE 4 | Location of proton magnetic resonance spectroscopy ( $\left.{ }^{1} \mathbf{H}-\mathbf{M R S}\right)$ voxels. (A) Axial localizer slice indicating the location of the midline anterior cingulate voxel. This voxel encompasses the pregenual ACC of both cerebral hemispheres. (B) Coronal localizer slice indicating the location of the left primary motor cortex voxel. The arrowhead indicates the vitamin E capsule which was placed directly over the abductor pollicis brevis (APB) point as determined by TMS. (C) Axial oblique localizer slice showing another view of the left primary motor cortex voxel. The center of the voxel is located immediately beneath the vitamin $\mathrm{E}$ capsule, encompassing the hand knob area of the primary motor cortex.

histograms and Q-Q plots revealed substantial skewness in many of the distributions. In light of the small sample size and low power to reject a null hypothesis of normality, we elected to report both the parametric Pearson product-moment correlation coefficient $(r)$ and the non-parametric Spearman rank-order correlation coefficient $(\rho)$ for all correlations between TMS measures and $[\mathrm{Glx}]$. As this was an exploratory study aimed at detecting signals of relationships of interest for hypothesis generation, uncorrected $p$-values are reported and interpreted. However, for the interested reader, adjustment of $p$-values for multiple comparisons using the false discovery rate (FDR) method (Benjamini and Hochberg, 1995) was performed, and these are reported as well. JMP 10.0.0 software (SAS Institute, Inc., Cary, NC, USA) was utilized for all statistical analyses.

\section{RESULTS}

\section{Participants}

Twenty-four adolescents (16 female, 8 male) with a mean age of $15.2 \pm 1.8$ years enrolled in the study. Of these, 14 participants (11 female, 3 male; mean age $14.7 \pm 1.9$ years) completed ${ }^{1} \mathrm{H}$-MRS procedures. Participant demographics, including mean depression severity scores on the CDRS-R and QIDS- $\mathrm{A}_{17-}$ $\mathrm{SR}$, are reported in Table 1. Fifteen participants were taking psychotropic medications at the time of the study; this included 14 taking selective serotonin reuptake inhibitors, two taking psychostimulants (which were held on days of TMS and ${ }^{1} \mathrm{H}$ MRS testing), one taking an atypical antipsychotic agent, and two taking sedative-hypnotics. For a full list of participants' psychotropic medications and doses at the time of the study, see Supplementary Table S1.

\section{TMS and MRS Measures}

Mean values and standard deviations for the TMS measures (RMT, CSP, SICI-2, SICI-4, ICF-10, ICF-15, and ICF-20) are reported in Table 2. In the left primary motor cortex, mean [Glx] obtained via ${ }^{1} \mathrm{H}-\mathrm{MRS}$ was $11.35 \pm 1.42$ institutional units. In the medial ACC, mean [Glx] was $18.45 \pm 5.03$. Other neural metabolite concentrations obtained via ${ }^{1} \mathrm{H}$-MRS are reported in Supplementary Materials (Table S2).

\section{Cortical Excitability and Inhibition-Cortical Glutamate Relationships}

\section{Left Primary Motor Cortex}

There was a significant positive correlation between RMT and left motor cortex [Glx] $(r=0.6533, p=0.0113$; $\rho=0.6300, p=0.0158)$. Other relationships between TMS measures and left motor cortex [Glx] were not significant (Table 3).

\section{Medial Anterior Cingulate Cortex}

The MEP amplitude in the 10-ms ICF paradigm (ICF-10) had a significant positive relationship with $[\mathrm{Glx}](\rho=0.6364$,

TABLE 1 | Participant demographics.

\begin{tabular}{lcc}
\hline & All participants & ${ }^{\mathbf{1}} \mathbf{H}-\mathbf{M R S}$ participants \\
\hline Sex & & \\
$\quad$ Female & $n=16$ & $n=11$ \\
$\quad$ Male & $n=8$ & $n=3$ \\
$\quad$ Age & $15.2 \pm 1.8$ years & $14.7 \pm 1.9$ years \\
Ethnicity & & \\
$\quad$ African-American & $n=2$ & $n=1$ \\
African-American/Caucasian & $n=1$ & $n=1$ \\
$\quad$ Asian & $n=2$ & $n=1$ \\
Caucasian & $n=17$ & $n=9$ \\
Hispanic & $n=1$ & $n=1$ \\
$\quad$ Native American & $n=1$ & $n=1$ \\
CDRS-R score & $39.2 \pm 13.0$ & $41.5 \pm 14.4$ \\
QIDS-A 17 -SR score & $11.5 \pm 5.2$ & $11.9 \pm 5.9$
\end{tabular}


TABLE 2 | Excitatory and inhibitory TMS measures.

\begin{tabular}{lll}
\hline & All participants & \\
\hline RMT & $60.79 \pm 11.94$ & $60.43 \pm 11.75$ \\
CSP & $0.190 \pm 0.051 \mathrm{~s}$ & $0.194 \pm 0.061 \mathrm{~s}$ \\
SICl-2 & $0.440 \pm 0.314$ & $0.495 \pm 0.358$ \\
SICl-4 & $0.578 \pm 0.296$ & $0.474 \pm 0.279$ \\
ICF-10 & $1.568 \pm 0.465$ & $1.455 \pm 0.367$ \\
ICF-15 & $1.765 \pm 0.447$ & $1.681 \pm 0.413$ \\
ICF-20 & $2.299 \pm 0.699$ & $2.472 \pm 0.698$
\end{tabular}

Abbreviations: RMT, resting motor threshold; CSP, cortical silent period; SICl-2, -4 , short-interval intracortical inhibition at 2-ms and 4-ms interstimulus intervals, respectively; ICF-10, -15, -20, intracortical facilitation at 10-ms, 15-ms and -20-ms interstimulus intervals, respectively. RMT is expressed as a percentage of maximal device output. MEP amplitudes in the SICI and ICF paradigms are expressed as ratios to the mean unconditioned stimulus amplitude.

$p=0.0261)$ in the medial ACC. Additionally, the MEP amplitude in the 20-ms ICF paradigm (ICF-20) demonstrated a significant positive correlation with [Glx] $(r=0.7201, p=0.0083)$. Correlations between ACC [Glx] and other TMS measures were not significant (Table 3).

\section{DISCUSSION}

This was an exploratory study investigating the potential link between glutamatergic neurochemistry and excitatory and inhibitory neurophysiology. To our knowledge, this was the first study to examine relationships between ${ }^{1} \mathrm{H}$-MRS-measured concentrations of neural metabolites and TMS measures of cortical excitation and inhibition in a psychiatric population, as well as the first to characterize these relationships in adolescents. Additionally, unlike prior TMS-MRS studies, neural metabolite concentration values were corrected to CSF. This eliminates the potential distortion that may be caused by correcting values to creatine, whose concentration may be altered in pathological conditions (Maddock and Buonocore, 2012) and indeed has been found to differ in adults with mood disorders (Frye et al., 2007; Port et al., 2008) as well as adolescents with MDD (Gabbay et al., 2007) and other psychopathology (Mirza et al., 2006).

\section{Motor Cortex Glutamate and Cortical Excitability}

The question of whether properties of TMS-induced MEPs originating in the primary motor cortex correspond to neurotransmitter levels in the same region of cortex is intuitive, and indeed these relationships have been the focus of two prior studies in healthy adults and one study in adults with mild brain injury. Stagg et al. (2011) investigated the relationships of GABA and glutamate concentrations in the motor cortex to various TMS measures of excitability and inhibition. The authors found that the MEP I-O curve, considered to be a global measure of excitability, was positively correlated with both motor cortex glutamate and motor cortex GABA concentrations; however, the MEP I-O-glutamate relationship did not survive correction for GABA concentration. In another study, Tremblay et al. (2013) noted a significant positive association between the CSP duration and motor cortex $[\mathrm{Glx}]$, a relationship that remained significant after controlling for GABA concentration. No significant correlations between ${ }^{1} \mathrm{H}$-MRS-measured [GABA] and CSP, SICI, or LICI were found. In another study, Tremblay et al. (2014) found a correlation between LICI and motor cortex [GABA] in young adult athletes with histories of concussion, a relationship that was absent in healthy control comparators, suggesting potential alterations in GABA-mediated inhibitory physiology due to brain pathology.

In the present study, we found a strong correlation between the RMT and motor cortex [Glx]. Interestingly, the relationship was positive (i.e., higher levels of [Glx] corresponded to higher thresholds for evoked potentials), which is somewhat counterintuitive and also differs from the direction of the relationship between RMT and ACC glutamate concentration (which did not quite meet the threshold for significance). Numerous factors could account for this. The physiology of the RMT is complex; both cortico-cortical and corticospinal neurons are involved (Sandbrink, 2008), and both voltage-gated sodium channels and glutamatergic receptors have been demonstrated to mediate the threshold level (Ziemann et al., 2015). The RMT may best be described

TABLE 3 | Correlations between ${ }^{1} \mathrm{H}$-MRS-measured glutamatergic metabolite concentrations and TMS measures of cortical excitability and inhibition.

\begin{tabular}{|c|c|c|c|c|c|c|c|c|c|c|c|c|}
\hline & \multicolumn{6}{|c|}{ Left primary motor cortex [GIx] } & \multicolumn{6}{|c|}{ Medial anterior cingulate cortex [GIx] } \\
\hline & Pearson $r$ & $p$ & $p_{\mathrm{FDR}}$ & Spearman $\rho$ & $p$ & $p_{\mathrm{FDR}}$ & Pearson $r$ & $p$ & $p_{\mathrm{FDR}}$ & Spearman $\rho$ & $p$ & $p_{\mathrm{FDR}}$ \\
\hline RMT & 0.6533 & $0.0113^{*}$ & 0.0791 & 0.6300 & $0.0158^{*}$ & 0.1827 & -0.4027 & 0.1943 & 0.3022 & -0.5149 & 0.0867 & 0.2616 \\
\hline CSP & -0.0635 & 0.8293 & 0.8931 & -0.1824 & 0.5325 & 0.6777 & -0.1373 & 0.6704 & 0.8532 & -0.2657 & 0.4038 & 0.5653 \\
\hline SICl-2 & 0.0990 & 0.7363 & 0.8590 & 0.0725 & 0.8054 & 0.8403 & 0.4414 & 0.1508 & 0.2639 & 0.4615 & 0.1309 & 0.2618 \\
\hline $\mathrm{SICl}-4$ & 0.5093 & 0.0629 & 0.2639 & 0.4593 & 0.0985 & 0.2616 & -0.1504 & 0.6408 & 0.8532 & -0.1469 & 0.6488 & 0.7569 \\
\hline ICF-10 & -0.4123 & 0.1429 & 0.2639 & -0.4901 & 0.0752 & 0.2616 & 0.4742 & 0.1193 & 0.2639 & 0.6364 & $0.0261^{*}$ & 0.1827 \\
\hline ICF-15 & 0.0045 & 0.9879 & 0.9879 & -0.0593 & 0.8403 & 0.8403 & -0.4753 & 0.1184 & 0.2639 & -0.4825 & 0.1121 & 0.2616 \\
\hline ICF-20 & -0.4704 & 0.0896 & 0.2639 & -0.3890 & 0.1692 & 0.2961 & 0.7201 & 0.0083* & 0.0791 & 0.4056 & 0.1908 & 0.2968 \\
\hline
\end{tabular}

${ }^{*} p$ < 0.05. Abbreviations: [GIx], glutamate+glutamine; RMT, resting motor threshold; CSP, cortical silent period; SICl-2, -4, short-interval intracortical inhibition at 2-ms and 4-ms interstimulus intervals, respectively; ICF-10, -15, -20, intracortical facilitation at 10-ms, 15-ms and 20-ms interstimulus intervals, respectively; pFDR, p-value corrected for multiple comparisons by the false discovery rate procedure. 
as a global index of cortical and spinal excitability that has many inputs, including glutamate-mediated neurotransmission. Thus, it perhaps would be overly simplistic to assume that an increase in glutamate necessarily leads to a decrease in RMT, as autoregulatory feedback loops and other mechanisms may mediate the effect of local glutamate concentration on the RMT. Furthermore, concentrations of glutamate or glutamate + glutamine in a region of cortex may not be particularly accurate indices of the pool of glutamate available for excitatory functions. Vesicular glutamate is not well detected by ${ }^{1} \mathrm{H}-\mathrm{MRS}$, and the concentrations measured by the current spectroscopic techniques may better represent the total neuronal and glial stores of glutamate and glutamine available for both synaptic and metabolic functions (Yüksel and Öngür, 2010; Maddock and Buonocore, 2012). Magnetic fields greater than the $3 \mathrm{~T}$ employed for ${ }^{1} \mathrm{H}$-MRS in this study are necessary to separate signals for glutamine and glutamate reliably. Additionally, there is growing recognition of the role of neuroactive chemicals in the extracellular matrix on intercellular communication in the brain (Marcoli et al., 2015). Nevertheless, it is notable that glutamatergic metabolites in the primary motor cortex demonstrated associations with the RMT, and further research is necessary to characterize the mechanisms by which glutamate mediates this aspect of excitatory physiology.

\section{ACC Glutamate and Cortical Excitability}

The few prior studies that examined relationships between TMS measures of cortical excitability and inhibition and cortical glutamatergic concentrations selected ${ }^{1} \mathrm{H}$-MRS voxels only in the motor cortex. There is robust evidence from prior ${ }^{1} \mathrm{H}$-MRS studies that glutamate metabolism in the ACC is disrupted in youth with MDD (Mirza et al., 2004; Rosenberg et al., 2004, 2005; Kondo et al., 2011), but it is not clear what effect this has on physiologic functions mediated by the motor cortex. Consequently, we investigated the relationships between ACC glutamate concentrations and TMS measures of cortical excitability and inhibition.

ACC $[\mathrm{Glx}]$ did not demonstrate significant correlations with inhibitory measures (CSP, SICI). However, [Glx] did demonstrate a strong positive correlation with MEP amplitude in the 10-ms ICF paradigm (in nonparametric correlations) and in the 20-ms paradigm (parametric), with higher concentrations of glutamate in the ACC corresponding to greater facilitation of the MEP. One should be cautious in assuming that increases in excitatory neurotransmitters in one area of cortex necessarily lead to increased excitatory physiology in another region. Nonetheless, these findings suggest that increased glutamate (or increased glutamate + glutamine stores) in the ACC may have downstream effects on the excitatory physiology mediated by the motor cortex, which is plausible in light of the dense connectivity between these two cortical regions (Paus, 2001). Replication, particularly in healthy control adolescents, would help to establish such a relationship. It is unclear why the nonsignificant ICF-ACC glutamate correlation was negative at the $15-\mathrm{ms}$ ISI, but this could be related to subtle differences in the physiology of facilitatory responses at different ISIs, something that has been observed with GABA-mediated SICI paradigms (Fisher et al., 2002; Ilić et al., 2002; Hanajima et al., 2003; Stagg et al., 2011).

In contrast to these ICF findings, the correlation between ACC glutamate and the RMT, which did not quite reach significance, was negative. This differs from the statistically significant, positive correlation between the RMT and [Glx] in the primary motor cortex. The negative relationship observed between glutamate concentrations in the ACC and the RMT could be related to glutamate-mediated regulatory circuits between the ACC and the motor cortex. As noted above, the physiology of the RMT involves many elements, notably the voltage-gated sodium channels, and it is possible that within the motor cortex these dominate the excitability responsible for motor threshold, with glutamate playing a lesser role. Future studies investigating the relationship between ACC glutamate and TMS measures of cortical excitability in healthy adolescent populations may help to understand the excitatory physiology of ACC-motor cortex connections further.

\section{Limitations}

The current study has several notable limitations. First, the sample size was small, particularly the subset that completed both TMS and ${ }^{1} \mathrm{H}$-MRS procedures. Although similar in size to the few previous TMS-MRS studies, this limited our statistical approaches. Correlations that were significant based on raw $p$-values did not survive correction for multiple comparisons, which is unsurprising in light of the number of correlations performed and the small number of participants. Thus, the findings should be interpreted with caution. Larger studies with greater power are warranted, particularly as this could permit controlling for potential confounds. Additionally, the sample did not include healthy controls. In the absence of data from healthy youth, it is not possible to determine to what extent depression may impact these findings, and future studies should endeavor to compare healthy participants and participants with psychopathology. The participants in this study were not medication-naïve, unlike many of the previous studies utilizing ${ }^{1} \mathrm{H}$-MRS or TMS methods. Although concurrent psychotropic medications or history of pharmacologic interventions do pose potential confounds, the sample of our study is potentially more representative of populations seen in typical clinical practice. An additional potential confound is the impact of the menstrual cycle on both TMS and ${ }^{1} \mathrm{H}-\mathrm{MRS}$ data, particularly as the sample was comprised predominantly of female adolescents. Prior TMS research has shown cortical inhibition to increase during the luteal phase in healthy women (Smith et al., 1999, 2003) but to decrease in women with premenstrual dysphoria (Smith et al., 2003), and ${ }^{1} \mathrm{H}$-MRS studies have shown alterations in cortical GABA levels across the menstrual cycle (Epperson et al., 2002, 2005; Harada et al., 2011). While menstrual phase and sex hormone levels were not assessed in the female adolescent participants in the present study, future investigations should 
consider the value of additional measures to assess and control for sex- and menstrual-related effects.

Previous research has established that significant changes occur in excitatory and inhibitory circuitry systems during the childhood and adolescent years. In early life, expression of various subunits that compose $\mathrm{GABA}_{\mathrm{A}}$ receptors has been found to change over time (Duncan et al., 2010), while $\mathrm{GABA}_{\mathrm{A}}$ receptor density changes at differing rates in various brain regions into adulthood (Chugani et al., 2001). GABA receptors also show paradoxically excitatory activity in early childhood, with a gradual shift toward inhibition with age (Rakhade and Jensen, 2009). Glutamatergic neurotransmission also undergoes developmental shifts, including alterations in expression of glutamatergic receptor types, as well as modifications in receptor subunit composition affecting ion permeability (Silverstein and Jensen, 2007). In the TMS literature, one of the most consistent age-related findings is that the RMT diminishes with increasing age, both in neurologically- and psychiatricallyhealthy individuals (Nezu et al., 1997; Heinen et al., 1998; Moll et al., 1999; Garvey et al., 2003; Mall et al., 2004; Gilbert et al., 2011) as well as those with conditions such as attentiondeficit/hyperactivity disorder (Gilbert et al., 2011), Tourette syndrome (Moll et al., 2006), and MDD (Croarkin et al., 2014). The impact of age on inhibitory TMS measures is less clear, with some studies finding CSP duration (Heinen et al., 1998; Moll et al., 1999), SICI (Mall et al., 2004), and LICI (Croarkin et al., 2014) to increase with age, while others have found no significant relationship with age for CSP (Garvey et al., 2003; Gilbert et al., 2011; Croarkin et al., 2014) or SICI (Moll et al., 1999; Gilbert et al., 2004, 2011; Croarkin et al., 2014). The statistical methods of the present study do not permit controlling for age; however, future studies utilizing neurophysiologic TMS in children and adolescents could consider regression analyses with age as a covariate. Further research is warranted to characterize more conclusively the developmental trajectories of TMS-measured cortical excitability and inhibition in the context of MDD.

In the processing of ${ }^{1} \mathrm{H}$-MRS data, there are inherent challenges in separating signals for Glu, Gln and GABA. Our ${ }^{1} \mathrm{H}$-MRS procedures did not permit identification of a distinct GABA signal, in contrast to other TMS-MRS studies (Stagg et al., 2011; Tremblay et al., 2013, 2014). However, there is significant interaction between GABAergic and glutamatergic systems, both at the level of their neurochemical pathways and in the excitatory-inhibitory balance achieved by circuits of GABAergic and glutamatergic neurons. Additionally, the interpretation of glutamatergic metabolite concentration data is difficult, as ${ }^{1} \mathrm{H}$-MRS-measured concentrations reflect the combined neuronal and glial stores of glutamate and glutamine, and also are believed to represent primarily cytoplasmic (as opposed to mitochondrial or vesicular) concentrations (Maddock and Buonocore, 2012). While total quantities of glutamatergic metabolites would be expected to influence glutamate-mediated (and GABA-mediated) processes, neuronal vesicular glutamate concentrations may be more immediately related to the neurotransmission underlying the excitatory and inhibitory phenomena measured by TMS. Moreover, the spectroscopic data were obtained at a single point in time. This is relevant in light of evidence from human ${ }^{1} \mathrm{H}$-MRS studies in which glutamatergic metabolites have been demonstrated to fluctuate in response to sensory stimuli (Mullins et al., 2005; Mangia et al., 2007; Gussew et al., 2010) and physical activity (Maddock et al., 2011), suggesting that glutamate concentrations are state-dependent and dynamic (Maddock and Buonocore, 2012). Although the ${ }^{1} \mathrm{H}$-MRS data in the present study were obtained on the same day as TMS testing, they were not concurrent with the excitatory and inhibitory processes induced by TMS.

\section{CONCLUSION}

The preliminary evidence from this small study supports the role of glutamate in cortical excitatory processes that are measured by TMS. To our knowledge, this was the first study to utilize the combination of TMS and ${ }^{1} \mathrm{H}$-MRS in a psychiatric population as well as the first to do so with adolescents. Further research aimed at examining the relationships between glutamatergic metabolite concentrations measured by MRS and excitatory and inhibitory physiology measured by TMS is warranted. Combined TMS-MRS methods have potential utility for investigating developmental changes in excitatory and inhibitory processes in healthy youth, studying the pathophysiology of common neurodevelopmental psychiatric conditions such as MDD, and ultimately for the development of biomarkers in children and adolescents.

\section{AUTHOR CONTRIBUTIONS}

CPL, JDP, MAF, JLVV, SHA, MMH, ZJD, and PEC contributed to the design of the study and interpretation of data. CPL, JLVV, and PEC acquired the data; JDP processed and analyzed the spectroscopic data; CPL and PEC processed transcranial magnetic stimulation data; $\mathrm{CPL}$ and $\mathrm{PEC}$ completed statistical analyses; CPL, JDP, MAF, JLVV, SHA, MMH, ZJD, and PEC drafted, revised, critically reviewed and approved the final submitted draft of the manuscript.

\section{ACKNOWLEDGMENTS}

This project was supported by an investigator-initiated, Pfizer, Inc., ASPIRE Grant (WS1976243); a Mayo Clinic Department of Psychiatry and Psychology Small Grant Award; and the National Institute of Mental Health (K23 MH100266). The content is solely the responsibility of the authors and does not necessarily represent the official views of the National Institutes of Health.

\section{SUPPLEMENTARY MATERIAL}

The Supplementary Material for this article can be found online at: http://journal.frontiersin.org/article/10.3389/fncir. 2016.00098/full\#supplementary-material 


\section{REFERENCES}

Auer, D. P., Pütz, B., Kraft, E., Lipinski, B., Schill, J., and Holsboer, F. (2000). Reduced glutamate in the anterior cingulate cortex in depression: an in vivo proton magnetic resonance spectroscopy study. Biol. Psychiatry 47, 305-313. doi: 10.1016/s0006-3223(99)00159-6

Bajbouj, M., Lisanby, S. H., Lang, U. E., Danker-Hopfe, H., Heuser, I., and Neu, P. (2006). Evidence for impaired cortical inhibition in patients with unipolar major depression. Biol. Psychiatry 59, 395-400. doi: 10.1016/j.biopsych.2005. 07.036

Benjamini, Y., and Hochberg, Y. (1995). Controlling the false discovery rate: a practical and powerful approach to multiple testing. J. R. Stat. Soc. Series B Methodol. 57, 289-300.

Bernstein, I. H., Rush, A. J., Trivedi, M. H., Hughes, C. W., Macleod, L., Witte, B. P., et al. (2010). Psychometric properties of the Quick Inventory of Depressive Symptomatology in adolescents. Int. J. Methods Psychiatr. Res. 19, 185-194. doi: 10.1002/mpr.321

Bestmann, S., and Feredoes, E. (2013). Combined neurostimulation and neuroimaging in cognitive neuroscience: past, present and future. Ann. NY Acad. Sci. 1296, 11-30. doi: 10.1111/nyas.12110

Block, W., Träber, F., von Widdern, O., Metten, M., Schild, H., Maier, W., et al. (2009). Proton MR spectroscopy of the hippocampus at $3 \mathrm{~T}$ in patients with unipolar major depressive disorder: correlates and predictors of treatment response. Int. J. Neuropsychopharmacol. 12, 415-422. doi: 10. 1017/s1461145708009516

Cantello, R., Gianelli, M., Civardi, C., and Mutani, R. (1992). Magnetic brain stimulation: the silent period after the motor evoked potential. Neurology 42, 1951-1959. doi: 10.1212/WNL.42.10.1951

Chugani, D. C., Muzik, O., Juhász, C., Janisse, J. J., Ager, J., and Chugani, H. T. (2001). Postnatal maturation of human $\mathrm{GABA}_{\mathrm{A}}$ receptors measured with positron emission tomography. Ann. Neurol. 49, 618-626. doi: 10.1002/ana. 1003.abs

Croarkin, P. E., Levinson, A. J., and Daskalakis, Z. J. (2011). Evidence for GABAergic inhibitory deficits in major depressive disorder. Neurosci. Biobehav. Rev. 35, 818-825. doi: 10.1016/j.neubiorev.2010.10.002

Croarkin, P. E., Nakonezny, P. A., Husain, M. M., Melton, T., Buyukdura, J. S., Kennard, B. D., et al. (2013). Evidence for increased glutamatergic cortical facilitation in children and adolescents with major depressive disorder. JAMA Psychiatry 70, 291-299. doi: 10.1001/2013.jamapsychiatry. 24

Croarkin, P. E., Nakonezny, P. A., Lewis, C. P., Zaccariello, M. J., Huxsahl, J. E., Husain, M. M., et al. (2014). Developmental aspects of cortical excitability and inhibition in depressed and healthy youth: an exploratory study. Front. Hum. Neurosci. 8:669. doi: 10.3389/fnhum.2014.00669

Croarkin, P. E., Nakonezny, P. A., Wall, C. A., Murphy, L. L., Sampson, S. M., Frye, M. A., et al. (2016). Transcranial magnetic stimulation potentiates glutamatergic neurotransmission in depressed adolescents. Psychiatry Res. Neuroim. 247, 25-33. doi: 10.1016/j.pscychresns.2015.11.005

Day, B. L., Marsden, C. D., Rothwell, J. C., Thompson, P. D., and Ugawa, Y. (1989a). An investigation of the EMG silent period following stimulation of the brain in normal man. J. Physiol. 414:14P.

Day, B. L., Rothwell, J. C., Thompson, P. D., Maertens de Noordhout, A., Nakashima, K., Shannon, K., et al. (1989b). Delay in the execution of voluntary movement by electrical or magnetic brain stimulation in intact man. Evidence for the storage of motor programs in the brain. Brain 112, 649-663. doi: 10 . 1093/brain/112.3.649

Devinsky, O., Morrell, M. J., and Vogt, B. A. (1995). Contributions of anterior cingulate cortex to behaviour. Brain 118, 279-306. doi: 10.1093/brain/ 118.1.279

Di Lazzaro, V., Oliviero, A., Meglio, M., Cioni, B., Tamburrini, G., Tonali, P., et al. (2000). Direct demonstration of the effect of lorazepam on the excitability of the human motor cortex. Clin. Neurophysiol. 111, 794-799. doi: 10.1016/s13882457(99)00314-4

Di Lazzaro, V., Oliviero, A., Profice, P., Pennisi, M. A., Pilato, F., Zito, G., et al. (2003). Ketamine increases human motor cortex excitability to transcranial magnetic stimulation. J. Physiol. 547, 485-496. doi: 10.1113/jphysiol.2002. 030486

Di Lazzaro, V., Oliviero, A., Saturno, E., Dileone, M., Pilato, F., Nardone, R., et al. (2005). Effects of lorazepam on short latency afferent inhibition and short latency intracortical inhibition in humans. J. Physiol. 564, 661-668. doi: 10. 1113/jphysiol.2004.061747

Di Lazzaro, V., Pilato, F., Dileone, M., Profice, P., Ranieri, F., Ricci, V., et al. (2007). Segregating two inhibitory circuits in human motor cortex at the level of GABA $A_{A}$ receptor subtypes: a TMS study. Clin. Neurophysiol. 118, 2207-2214. doi: 10.1016/j.clinph.2007.07.005

Di Lazzaro, V., Pilato, F., Oliviero, A., Dileone, M., Saturno, E., Mazzone, P., et al. (2006). Origin of facilitation of motor-evoked potentials after paired magnetic stimulation: direct recording of epidural activity in conscious humans. J. Neurophysiol. 96, 1765-1771. doi: 10.1152/jn.00360.2006

Di Lazzaro, V., Restuccia, D., Oliviero, A., Profice, P., Ferrara, L., Insola, A., et al. (1998). Magnetic transcranial stimulation at intensities below active motor threshold activates intracortical inhibitory circuits. Exp. Brain Res. 119, 265-268. doi: 10.1007/s002210050341

Dubin, M. J., Mao, X., Banerjee, S., Goodman, Z., Lapidus, K. A., Kang, G., et al. (2016). Elevated prefrontal cortex GABA in patients with major depressive disorder after TMS treatment measured with proton magnetic resonance spectroscopy. J. Psychiatry Neurosci. 41, E37-E45. doi: 10.1503/jpn. 150223

Duncan, C. E., Webster, M. J., Rothmond, D. A., Bahn, S., Elashoff, M., and Shannon Weickert, C. (2010). Prefrontal GABA A receptor $\alpha$-subunit expression in normal postnatal human development and schizophrenia. J. Psychiatr. Res. 44, 673-681. doi: 10.1016/j.jpsychires.2009. 12.007

Epperson, C. N., Haga, K., Mason, G. F., Sellers, E., Gueorguieva, R., Zhang, W., et al. (2002). Cortical $\gamma$-aminobutyric acid levels across the menstrual cycle in healthy women and those with premenstrual dysphoric disorder: a proton magnetic resonance spectroscopy study. Arch. Gen. Psychiatry 59, 851-858. doi: 10.1001/archpsyc.59.9.851

Epperson, C. N., O’Malley, S., Czarkowski, K. A., Gueorguieva, R., Jatlow, P., Sanacora, G., et al. (2005). Sex, GABA, and nicotine: the impact of smoking on cortical GABA levels across the menstrual cycle as measured with proton magnetic resonance spectroscopy. Biol. Psychiatry 57, 44-48. doi: 10.1016/j. biopsych.2004.09.021

Fisher, R. J., Nakamura, Y., Bestmann, S., Rothwell, J. C., and Bostock, H. (2002). Two phases of intracortical inhibition revealed by transcranial magnetic threshold tracking. Exp. Brain Res. 143, 240-248. doi: 10.1007/s00221-0010988-2

Frye, M. A., Watzl, J., Banakar, S., O’Neill, J., Mintz, J., Davanzo, P., et al. (2007). Increased anterior cingulate/medial prefrontal cortical glutamate and creatine in bipolar depression. Neuropsychopharmacology 32, 2490-2499. doi: 10. 1038/sj.npp.1301387

Fuhr, P., Agostino, R., and Hallett, M. (1991). Spinal motor neuron excitability during the silent period after cortical stimulation. Electroencephalogr. Clin. Neurophysiol. 81, 257-262. doi: 10.1016/0168-5597(91) 90011-1

Gabbay, V., Hess, D. A., Liu, S., Babb, J. S., Klein, R. G., and Gonen, O. (2007). Lateralized caudate metabolic abnormalities in adolescent major depressive disorder: a proton MR spectroscopy study. Am. J. Psychiatry 164, 1881-1889. doi: 10.1176/appi.ajp.2007.06122032

Garvey, M. A., Ziemann, U., Bartko, J. J., Denckla, M. B., Barker, C. A., and Wassermann, E. M. (2003). Cortical correlates of neuromotor development in healthy children. Clin. Neurophysiol. 114, 1662-1670. doi: 10.1016/s13882457(03)00130-5

Gilbert, D. L., Bansal, A. S., Sethuraman, G., Sallee, F. R., Zhang, J., Lipps, T., et al. (2004). Association of cortical disinhibition with tic, ADHD, and OCD severity in Tourette syndrome. Mov. Disord. 19, 416-425. doi: 10.1002/mds. 20044

Gilbert, D. L., Isaacs, K. M., Augusta, M., MacNeil, L. K., and Mostofsky, S. H. (2011). Motor cortex inhibition: a marker of ADHD behavior and motor development in children. Neurology 76, 615-621. doi: 10.1212/WNL. 0b013e31820c2ebd

Gussew, A., Rzanny, R., Erdtel, M., Scholle, H. C., Kaiser, W. A., Mentzel, H. J., et al. (2010). Time-resolved functional ${ }^{1} \mathrm{H}$ MR spectroscopic detection of glutamate concentration changes in the brain during acute heat pain stimulation. Neuroimage 49, 1895-1902. doi: 10.1016/j.neuroimage.2009. 09.007

Hanajima, R., Furubayashi, T., Iwata, N. K., Shiio, Y., Okabe, S., Kanazawa, I., et al. (2003). Further evidence to support different mechanisms underlying 
intracortical inhibition of the motor cortex. Exp. Brain Res. 151, 427-434. doi: $10.1007 / \mathrm{s} 00221-003-1455-\mathrm{z}$

Hanajima, R., and Ugawa, Y. (2008). "Paired-pulse measures," in The Oxford Handbook of Transcranial Stimulation, eds. E. M. Wassermann, C. M. Epstein, U. Ziemann, V. Walsh, T. Paus and S. H. Lisanby (Oxford: Oxford University Press), 103-118.

Hanajima, R., Ugawa, Y., Terao, Y., Sakai, K., Furubayashi, T., Machii, K., et al. (1998). Paired-pulse magnetic stimulation of the human motor cortex: differences among I waves. J. Physiol. 509, 607-618. doi: 10.1111/j.1469-7793. 1998.607bn.x

Harada, M., Kubo, H., Nose, A., Nishitani, H., and Matsuda, T. (2011). Measurement of variation in the human cerebral GABA level by in vivo MEGA-editing proton MR spectroscopy using a clinical $3 \mathrm{~T}$ instrument and its dependence on brain region and the female menstrual cycle. Hum. Brain Mapp. 32, 828-833. doi: 10.1002/hbm.21086

Hasler, G., Neumeister, A., van der Veen, J. W., Tumonis, T., Bain, E. E., Shen, J., et al. (2005). Normal prefrontal gamma-aminobutyric acid levels in remitted depressed subjects determined by proton magnetic resonance spectroscopy. Biol. Psychiatry 58, 969-973. doi: 10.1016/j.biopsych.2005.05.017

Hasler, G., van der Veen, J. W., Tumonis, T., Meyers, N., Shen, J., and Drevets, W. C. (2007). Reduced prefrontal glutamate/glutamine and $\gamma$-aminobutyric acid levels in major depression determined using proton magnetic resonance spectroscopy. Arch. Gen. Psychiatry 64, 193-200. doi: 10. 1001/archpsyc.64.2.193

Heinen, F., Glocker, F.-X., Fietzek, U., Meyer, B.-U., Lücking, C.-H., and Korinthenberg, R. (1998). Absence of transcallosal inhibition following focal magnetic stimulation in preschool children. Ann. Neurol. 43, 608-612. doi: 10. 1002/ana.410430508

Horn, D. I., Yu, C., Steiner, J., Buchmann, J., Kaufmann, J., Osoba, A., et al. (2010). Glutamatergic and resting-state functional connectivity correlates of severity in major depression-the role of pregenual anterior cingulate cortex and anterior insula. Front. Syst. Neurosci. 4:33. doi: 10.3389/fnsys.2010. 00033

Ilić, T. V., Meintzschel, F., Cleff, U., Ruge, D., Kessler, K. R., and Ziemann, U. (2002). Short-interval paired-pulse inhibition and facilitation of human motor cortex: the dimension of stimulus intensity. J. Physiol. 545, 153-167. doi: 10. 1113/jphysiol.2002.030122

Keel, J. C., Smith, M. J., and Wassermann, E. M. (2001). A safety screening questionnaire for transcranial magnetic stimulation. Clin. Neurophysiol. 112:720. doi: 10.1016/s1388-2457(00)00518-6

Kondo, D. G., Hellem, T. L., Sung, Y. H., Kim, N., Jeong, E.-K., DelMastro, K. K., et al. (2011). Review: magnetic resonance spectroscopy studies of pediatric major depressive disorder. Depress. Res. Treat. 2011:650450. doi: 10. $1155 / 2011 / 650450$

Kreis, R. (2016). The trouble with quality filtering based on relative CramérRao lower bounds. Magn. Reson. Med. 75, 15-18. doi: 10.1002/mrm. 25568

Krystal, J. H., Sanacora, G., Blumberg, H., Anand, A., Charney, D. S., Marek, G., et al. (2002). Glutamate and GABA systems as targets for novel antidepressant and mood-stabilizing treatments. Mol. Psychiatry 7, S71-S80. doi: 10.1038/sj. mp.4001021

Kujirai, T., Caramia, M. D., Rothwell, J. C., Day, B. L., Thompson, P. D., Ferbert, A., et al. (1993). Corticocortical inhibition in human motor cortex. J. Physiol. 471, 501-519. doi: 10.1113/jphysiol.1993.sp019912

Lefaucheur, J. P., Lucas, B., Andraud, F., Hogrel, J. Y., Bellivier, F., Del Cul, A., et al. (2008). Inter-hemispheric asymmetry of motor corticospinal excitability in major depression studied by transcranial magnetic stimulation. J. Psychiatr. Res. 42, 389-398. doi: 10.1016/j.jpsychires.2007.03.001

Levinson, A. J., Fitzgerald, P. B., Favalli, G., Blumberger, D. M., Daigle, M., and Daskalakis, Z. J. (2010). Evidence of cortical inhibitory deficits in major depressive disorder. Biol. Psychiatry 67, 458-464. doi: 10.1016/j.biopsych.2009. 09.025

Lewis, C. P., Nakonezny, P. A., Ameis, S. H., Vande Voort, J. L., Husain, M. M., Emslie, G. J., et al. (2016). Cortical inhibitory and excitatory correlates of depression severity in children and adolescents. J. Affect. Disord. 190, 566-575. doi: 10.1016/j.jad.2015.10.020

Liepert, J., Schwenkreis, P., Tegenthoff, M., and Malin, J.-P. (1997). The glutamate antagonist riluzole suppresses intracortical facilitation. J. Neural Transm. 104, 1207-1214. doi: 10.1007/BF01294721
Maddock, R. J., and Buonocore, M. H. (2012). MR spectroscopic studies of the brain in psychiatric disorders. Curr. Top. Behav. Neurosci. 11, 199-251. doi: 10. 1007/7854_2011_197

Maddock, R. J., Casazza, G. A., Buonocore, M. H., and Tanase, C. (2011). Vigorous exercise increases brain lactate and Glx (glutamate+glutamine): a dynamic 1H-MRS study. Neuroimage 57, 1324-1330. doi: 10.1016/j.neuroimage.2011. 05.048

Mall, V., Berweck, S., Fietzek, U. M., Glocker, F.-X., Oberhuber, U., Walther, M., et al. (2004). Low level of intracortical inhibition in children shown by transcranial magnetic stimulation. Neuropediatrics $35,120-125$. doi: $10.1055 / \mathrm{s}$ 2004-815834

Mangia, S., Tkáč, I., Gruetter, R., Van de Moortele, P.-F., Maraviglia, B., and Uğurbil, K. (2007). Sustained neuronal activation raises oxidative metabolism to a new steady-state level: evidence from ${ }^{1} \mathrm{H}$ NMR spectroscopy in the human visual cortex. J. Cereb. Blood Flow Metab. 27, 1055-1063. doi: 10.1038/sj.jcbfm. 9600401

Marcoli, M., Agnati, L. F., Benedetti, F., Genedani, S., Guidolin, D., Ferraro, L., et al. (2015). On the role of the extracellular space on the holistic behavior of the brain. Rev. Neurosci. 26, 489-506. doi: 10.1515/revneuro-2015-0007

Merkl, A., Schubert, F., Quante, A., Luborzewski, A., Brakemeier, E.-L., Grimm, S., et al. (2011). Abnormal cingulate and prefrontal cortical neurochemistry in major depression after electroconvulsive therapy. Biol. Psychiatry 69, 772-779. doi: 10.1016/j.biopsych.2010.08.009

Michael, N., Erfurth, A., Ohrmann, P., Arolt, V., Heindel, W., and Pfleiderer, B. (2003a). Metabolic changes within the left dorsolateral prefrontal cortex occurring with electroconvulsive therapy in patients with treatment resistant unipolar depression. Psychol. Med. 33, 1277-1284. doi: 10. 1017/s0033291703007931

Michael, N., Erfurth, A., Ohrmann, P., Arolt, V., Heindel, W., and Pfleiderer, B. (2003b). Neurotrophic effects of electroconvulsive therapy: a proton magnetic resonance study of the left amygdalar region in patients with treatmentresistant depression. Neuropsychopharmacology 28, 720-725. doi: 10.1038/sj. npp. 1300085

Mirza, Y., O’Neill, J., Smith, E. A., Russell, A., Smith, J. M., Banerjee, S. P., et al. (2006). Increased medial thalamic creatine-phosphocreatine found by proton magnetic resonance spectroscopy in children with obsessivecompulsive disorder versus major depression and healthy controls. J. Child Neurol. 21, 106-111. doi: 10.1177/08830738060210020201

Mirza, Y., Tang, J., Russell, A., Banerjee, S. P., Bhandari, R., Ivey, J., et al. (2004). Reduced anterior cingulate cortex glutamatergic concentrations in childhood major depression. J. Am. Acad. Child Adolesc. Psychiatry 43, 341-348. doi: 10. 1097/00004583-200403000-00017

Moll, G. H., Heinrich, H., Gevensleben, H., and Rothenberger, A. (2006). Tic distribution and inhibitory processes in the sensorimotor circuit during adolescence: a cross-sectional TMS study. Neurosci. Lett. 403, 96-99. doi: 10. 1016/j.neulet.2006. 04.021

Moll, G. H., Heinrich, H., Wischer, S., Tergau, F., Paulus, W., and Rothenberger, A. (1999). Motor system excitability in healthy children: developmental aspects from transcranial magnetic stimulation. Electroencephalogr. Clin. Neurophysiol. Suppl. 51, 243-249.

Mullins, P. G., Rowland, L. M., Jung, R. E., and Sibbitt, W. L. Jr. (2005). A novel technique to study the brain's response to pain: proton magnetic resonance spectroscopy. Neuroimage 26, 642-646. doi: 10.1016/j.neuroimage. 2005. 02.001

Nezu, A., Kimura, S., Uehara, S., Kobayashi, T., Tanaka, M., and Saito, K. (1997). Magnetic stimulation of motor cortex in children: maturity of corticospinal pathway and problem of clinical application. Brain Dev. 19, 176-180. doi: 10. 1016/s0387-7604(96)00552-9

Oldfield, R. C. (1971). The assessment and analysis of handedness: the Edinburgh inventory. Neuropsychologia 9, 97-113. doi: 10.1016/0028-3932(71) 90067-4

Paulus, W., Classen, J., Cohen, L. G., Large, C. H., Di Lazzaro, V., Nitsche, M., et al. (2008). State of the art: pharmacologic effects on cortical excitability measures tested by transcranial magnetic stimulation. Brain Stimul. 1, 151-163. doi: 10. 1016/j.brs.2008.06.002

Paus, T. (2001). Primate anterior cingulate cortex: where motor control, drive and cognition interface. Nat. Rev. Neurosci. 2, 417-424. doi: 10.1038/35077500

Pfleiderer, B., Michael, N., Erfurth, A., Ohrmann, P., Hohmann, U., Wolgast, M., et al. (2003). Effective electroconvulsive therapy reverses glutamate/glutamine 
deficit in the left anterior cingulum of unipolar depressed patients. Psychiatry Res. 122, 185-192. doi: 10.1016/s0925-4927(03)00003-9

Port, J. D., Unal, S. S., Mrazek, D. A., and Marcus, S. M. (2008). Metabolic alterations in medication-free patients with bipolar disorder: a $3 \mathrm{~T}$ CSF-corrected magnetic resonance spectroscopic imaging study. Psychiatry Res. 162, 113-121. doi: 10.1016/j.pscychresns.2007.08.004

Portella, M. J., de Diego-Adeliño, J., Gómez-Ansón, B., Morgan-Ferrando, R., Vives, Y., Puigdemont, D., et al. (2011). Ventromedial prefrontal spectroscopic abnormalities over the course of depression: a comparison among first episode, remitted recurrent and chronic patients. J. Psychiatr. Res. 45, 427-434. doi: 10. 1016/j.jpsychires.2010.08.010

Poznanski, E. O., Grossman, J. A., Buchsbaum, Y., Banegas, M., Freeman, L., and Gibbons, R. (1984). Preliminary studies of the reliability and validity of the children's depression rating scale. J. Am. Acad. Child Psychiatry 23, 191-197. doi: 10.1097/00004583-198403000-00011

Pratt, L. A., and Brody, D. J. (2014). Depression in the U.S. Household Population, 2009-2012. NCHS Data Brief No. 172. (Hyattsville, MD: National Center for Health Statistics).

Provencher, S. W. (1993). Estimation of metabolite concentrations from localized in vivo proton NMR spectra. Magn. Reson. Med. 30, 672-679. doi: 10. 1002/mrm.1910300604

Radhu, N., de Jesus, D. R., Ravindran, L. N., Zanjani, A., Fitzgerald, P. B., and Daskalakis, Z. J. (2013). A meta-analysis of cortical inhibition and excitability using transcranial magnetic stimulation in psychiatric disorders. Clin. Neurophysiol. 124, 1309-1320. doi: 10.1016/j.clinph.2013.01.014

Rakhade, S. N., and Jensen, F. E. (2009). Epileptogenesis in the immature brain: emerging mechanisms. Nat. Rev. Neurol. 5, 380-391. doi: 10.1038/nrneurol. 2009.80

Rosenberg, D. R., MacMaster, F. P., Mirza, Y., Smith, J. M., Easter, P. C., Banerjee, S. P., et al. (2005). Reduced anterior cingulate glutamate in pediatric major depression: a magnetic resonance spectroscopy study. Biol. Psychiatry 58, 700-704. doi: 10.1016/j.biopsych.2005.05.007

Rosenberg, D. R., Mirza, Y., Russell, A., Tang, J., Smith, J. M., Banerjee, S. P., et al. (2004). Reduced anterior cingulate glutamatergic concentrations in childhood OCD and major depression versus healthy controls. J. Am. Acad. Child Adolesc. Psychiatry 43, 1146-1153. doi: 10.1097/01.chi.0000132812.44664.2d

Rossini, P. M., Burke, D., Chen, R., Cohen, L. G., Daskalakis, Z., Di Iorio, R., et al. (2015). Non-invasive electrical and magnetic stimulation of the brain, spinal cord, roots and peripheral nerves: basic principles and procedures for routine clinical and research application. An updated report from an I.F.C.N. Committee. Clin. Neurophysiol. 126, 1071-1107. doi: 10.1016/j.clinph.2015. 02.001

Sanacora, G., Gueorguieva, R., Epperson, C. N., Wu, Y.-T., Appel, M., Rothman, D. L., et al. (2004). Subtype-specific alterations of $\gamma$-aminobutyric acid and glutamate in patients with major depression. Arch. Gen. Psychiatry 61, 705-713. doi: 10.1001/archpsyc.61.7.705

Sanacora, G., and Saricicek, A. (2007). GABAergic contributions to the pathophysiology of depression and the mechanism of antidepressant action. CNS Neurol. Disord. Drug Targets 6, 127-140. doi: 10. 2174/187152707780363294

Sandbrink, F. (2008). "The MEP in clinical neurodiagnosis," in The Oxford Handbook of Transcranial Stimulation, eds E. M. Wassermann, C. M. Epstein U. Ziemann, V. Walsh, T. Paus and S. H. Lisanby (Oxford: Oxford University Press), 237-283.

Schwenkreis, P., Liepert, J., Witscher, K., Fischer, W., Weiller, C., Malin, J.-P., et al. (2000). Riluzole suppresses motor cortex facilitation in correlation to its plasma level. A study using transcranial magnetic stimulation. Exp. Brain Res. 135, 293-299. doi: 10.1007/s002210000532

Schwenkreis, P., Witscher, K., Janssen, F., Addo, A., Dertwinkel, R., Zenz, M., et al. (1999). Influence of the N-methyl-D-aspartate antagonist memantine on human motor cortex excitability. Neurosci. Lett. 270, 137-140. doi: 10. 1016/s0304-3940(99)00492-9

Siebner, H. R., Dressnandt, J., Auer, C., and Conrad, B. (1998). Continuous intrathecal baclofen infusions induced a marked increase of the transcranially evoked silent period in a patient with generalized dystonia. Muscle Nerve 21, 1209-1212. doi: 10.1002/(SICI)1097-4598(199809)21:9<1209::AIDMUS15>3.0.CO;2-M

Silverstein, F. S., and Jensen, F. E. (2007). Neonatal seizures. Ann. Neurol. 62, 112-120. doi: 10.1002/ana.21167
Smith, M. J., Adams, L. F., Schmidt, P. J., Rubinow, D. R., and Wassermann, E. M. (2003). Abnormal luteal phase excitability of the motor cortex in women with premenstrual syndrome. Biol. Psychiatry 54, 757-762. doi: 10.1016/s00063223(02)01924-8

Smith, M. J., Keel, J. C., Greenberg, B. D., Adams, L. F., Schmidt, P. J., Rubinow, D. A., et al. (1999). Menstrual cycle effects on cortical excitability. Neurology 53, 2069-2072. doi: 10.1212/wnl.53.9.2069

Stagg, C. J., Bestmann, S., Constantinescu, A. O., Moreno Moreno, L., Allman, C., Mekle, R., et al. (2011). Relationship between physiological measures of excitability and levels of glutamate and GABA in the human motor cortex. J. Physiol. 589, 5845-5855. doi: 10.1113/jphysiol.2011.216978

Steele, J. D., Glabus, M. F., Shajahan, P. M., and Ebmeier, K. P. (2000). Increased cortical inhibition in depression: a prolonged silent period with transcranial magnetic stimulation (TMS). Psychol. Med. 30, 565-570. doi: 10. $1017 /$ s0033291799002032

Taylor, M. J., Selvaraj, S., Norbury, R., Jezzard, P., and Cowen, P. J. (2009). Normal glutamate but elevated myo-inositol in anterior cingulate cortex in recovered depressed patients. J. Affect. Disord. 119, 186-189. doi: 10.1016/j.jad.2009. 02.022

Tremblay, S., Beaulé, V., Proulx, S., de Beaumont, L., Marjańska, M., Doyon, J., et al. (2013). Relationship between transcranial magnetic stimulation measures of intracortical inhibition and spectroscopy measures of GABA and glutamate+glutamine. J. Neurophysiol. 109, 1343-1349. doi: 10.1152/jn.00704. 2012

Tremblay, S., Beaulé, V., Proulx, S., Tremblay, S., Marjańska, M., Doyon, J., et al. (2014). Multimodal assessment of primary motor cortex integrity following sport concussion in asymptomatic athletes. Clin. Neurophysiol. 125, 1371-1379. doi: 10.1016/j.clinph.2013.11.040

Werhahn, K. J., Kunesch, E., Noachtar, S., Benecke, R., and Classen, J. (1999). Differential effects on motorcortical inhibition induced by blockade of GABA uptake in humans. J. Physiol. 517, 591-597. doi: 10.1111/j.1469-7793.1999. 0591t.x

Wolters, A., Ziemann, U., and Benecke, R. (2008). "The cortical silent period," in The Oxford Handbook of Transcranial Stimulation, eds E. M. Wassermann C. M. Epstein U. Ziemann V. Walsh T. Paus and S. H. Lisanby (Oxford: Oxford University Press), 91-102.

Yildiz-Yesiloglu, A., and Ankerst, D. P. (2006). Review of ${ }^{1} \mathrm{H}$ magnetic resonance spectroscopy findings in major depressive disorder: a meta-analysis. Psychiatry Res. 147, 1-25. doi: 10.1016/j.pscychresns.2005.12.004

Yüksel, C., and Öngür, D. (2010). Magnetic resonance spectroscopy studies of glutamate-related abnormalities in mood disorders. Biol. Psychiatry 68, 785-794. doi: 10.1016/j.biopsych.2010.06.016

Zalsman, G., Oquendo, M. A., Greenhill, L., Goldberg, P. H., Kamali, M., Martin, A., et al. (2006). Neurobiology of depression in children and adolescents. Child Adolesc. Psychiatr. Clin. N Am. 15, 843-868, vii-viii. doi: 10. 1016/j.chc.2006.05.010

Ziemann, U. (2004). TMS and drugs. Clin. Neurophysiol. 115, 1717-1729. doi: 10. 1016/..clinph.2004.03.006

Ziemann, U., Chen, R., Cohen, L. G., and Hallett, M. (1998). Dextromethorphan decreases the excitability of the human motor cortex. Neurology 51, 1320-1324. doi: $10.1212 / \mathrm{wnl} .51 .5 .1320$

Ziemann, U., Lönnecker, S., Steinhoff, B. J., and Paulus, W. (1996a). The effect of lorazepam on the motor cortical excitability in man. Exp. Brain Res. 109, 127-135. doi: $10.1007 / \mathrm{bf} 00228633$

Ziemann, U., Rothwell, J. C., and Ridding, M. C. (1996b). Interaction between intracortical inhibition and facilitation in human motor cortex. J. Physiol. 496, 873-881. doi: 10.1113/jphysiol.1996.sp021734

Ziemann, U., Reis, J., Schwenkreis, P., Rosanova, M., Strafella, A., Badawy, R., et al. (2015). TMS and drugs revisited 2014. Clin. Neurophysiol. 126, 1847-1868. doi: 10.1016/j.clinph.2014.08.028

Conflict of Interest Statement: MAF has had grant support from Assurex, Myriad, and Pfizer and has served as an unpaid consultant for Janssen Global Services LLC, Mitsubishi Tanabe Pharma Corporation, Myriad, Sunovion, Supernus Pharmaceuticals, and Teva Pharmaceuticals. MMH has received grant support from Alkermes, Assurex, Avanir, Cyberonics, Brainsway, MagStim, NeoSync, Neuronetics, the Stanley Foundation, and St. Jude Medical (Advanced Neuromodulation Systems). He has received research and equipment in-kind support for an investigator-initiated study 
through Brainsway, and a travel allowance through Merck. ZJD received research and equipment in-kind support for an investigator-initiated study through Brainsway and a travel allowance through Merck. He has received speaker funding through Sepracor and AstraZeneca, served on advisory boards for Hoffmann-LaRoche Limited and Merck, and received speaker support from Eli Lilly. PEC has received investigator-initiated grant support through Pfizer and in-kind support from Assurex (supplies and genotyping for an investigator-initiated study) and Neuronetics (supplies for investigator-initiated studies). He is a site primary investigator for a multicenter trial sponsored by Neuronetics. CPL is a site co-investigator for a multicenter trial sponsored by Neuronetics.
JLVV is a site co-investigator for a multicenter trial sponsored by Neuronetics and has in-kind support from Assurex. The remaining authors declare no conflicts of interest.

Copyright (c) 2016 Lewis, Port, Frye, Vande Voort, Ameis, Husain, Daskalakis and Croarkin. This is an open-access article distributed under the terms of the Creative Commons Attribution License (CC BY). The use, distribution and reproduction in other forums is permitted, provided the original author(s) or licensor are credited and that the original publication in this journal is cited, in accordance with accepted academic practice. No use, distribution or reproduction is permitted which does not comply with these terms. 